\title{
Avaliação dos ungüentos à base de extratos hexânico ou etanólico das folhas de Momordica charantia L. sobre as lesões cutâneas experimentais em coelhos
}

\author{
Evaluation of the ointment containing the hexanic or ethanolic extracts of leaves \\ of Momordica charantia L. on experimental cutaneous wounds in rabbits \\ Ana Karinne Paiva Vasconcelos, Adriana Rocha Tomé, \\ Bárbara Sucupira Pereira \& Diana Célia Sousa Nunes-Pinheiro
}

\begin{abstract}
RESUMO
Entre as inúmeras plantas empregadas na medicina tradicional destaca-se a Momordica charantia, que vem ganhando notoriedade científica por suas diversas propriedades biológicas e farmacológicas. O objetivo deste trabalho foi investigar a regeneração de lesões cutâneas em coelhos, tratadas diariamente com ungüento contendo os extratos hexânico (EH) e etanólico (EE) das folhas de M.charantia nas concentrações de 10 e 20\%, comparadas com o controle (base do ungüento). Lesões cutâneas de cerca de $5 \mathrm{~mm}$ foram induzidas experimentalmente por um punch, tendo os coelhos sido anestesiados previamente e após 4 (D4) e 14 (D14) dias de tratamento, as lesões foram removidas cirurgicamente e encaminhadas para análise histopatológica. O processo de reparo cutâneo foi avaliado nestes intervalos de tempo através da observação macroscópica, mensuração da área de retração da ferida e avaliação microscópica através da contagem do número de células mononucleares e fibroblastos e dos vasos sanguíneos. O ungüento contendo o EH (10 e 20\%) demonstrou ser o mais eficaz por acelerar $(\mathrm{P}<0,01)$ o processo de regeneração cutânea. Isto demonstra o potencial farmacológico desta planta para uso Veterinário.
\end{abstract}

Descritores: Momordica charantia, Cucurbitaceae, cicatrização cutânea, análise histopatológica, observação macroscópica, coelhos.

\section{ABSTRACT}

Among the countless plants maids in the traditional medicine stands out the Momordica charantia, which is winning scientific fame, for many biological and pharmacological properties. This work investigated the healing process on excisional wounds in the skin of rabbits, treated daily with ointment containing 10 and $20 \%$ of the hexanic and ethanolic extracts of the leaves of M.charantia, compared with the control. A skin wound area of about $5 \mathrm{~mm}$ was excised trough of punch on anaesthetised rabbits and after 4 (D4) and 14 (D14) days of treatment, the lesions were surgically removed and histologically processed. Wound healing activity was determined by macroscopic observation, measure of the area of contraction and microscopic evaluation on the count of the number of fibroblasts and mononuclear inflammatory cells, and blood vessels. The ointment containing HE (10 and 20\%) was demonstrated effective for accelerating $(\mathrm{P}<0,01)$ the process of cutaneous regeneration. So, the results demonstrate the potential pharmacological of this plant for Veterinary use.

Key words: Momordica charantia, Cucurbitaceae, cutaneous cicatrization, histopathological analysis, macroscopic observation, rabbits. 


\section{INTRODUÇÃO}

A Momordica charantia L. é uma planta medicinal, pertencente à família Cucurbitaceae, que vêm ganhando espaço no cenário científico mundial. Constitui uma trepadeira, bastante comum no nordeste brasileiro, sendo popularmente conhecida por melão-deSão-Caetano. Estudos prévios comprovaram inúmeras propriedades farmacológicas desta planta como agente fitoterápico. Dentre estas, destacam-se sua atividade hipoglicemiante [16], antibacteriana [7], antiviral [9], antiHIV [1], antitumoral [2,14], anti-helmíntica [18] e abortiva [10]. Recentemente, tem aumentado o interesse por drogas obtidas a partir de plantas medicinais, destacando-se aquelas com potencialidade para promover a cicatrização de feridas.

O processo de cicatrização tecidual consiste de um fenômeno fisiológico que se inicia a partir da perda de integridade da pele, gerando uma solução de continuidade que atinge os planos subjacentes em diversos graus, e depende de uma série de reações químicas [6]. Este processo está classicamente dividido em três fases: inflamação, reparação e deposição de matriz extracelular e remodelação.

Existem relatos do uso popular da $M$. charantia como cicatrizante. No entanto, ainda não existe literatura que comprove a atividade cicatrizante da aplicação tópica de extratos desta planta in vivo.

Desta forma, o presente trabalho propõe avaliar ungüentos à base de extrato hexânico $(\mathrm{EH})$ ou etanólico (EE) de $M$. charantia na regeneração de feridas cutâneas de coelhos.

\section{MATERIAIS E MÉTODOS}

\section{Material vegetal e preparação do extrato}

As folhas de $M$. charantia foram coletadas pela manhã no mês de maio de 2005, na cidade de Fortaleza, Estado do Ceará, Nordeste do Brasil. A identificação botânica da planta foi realizada no Herbário Prisco Bezerra do Departamento de Botânica e Biologia da Universidade Federal do Ceará, recebendo o voucher 32441.

Folhas secas $(150 \mathrm{~g})$ da planta foram colocadas em um balão de vidro com $500 \mathrm{ml}$ de hexano, por 7 dias na ausência de luz. Em seguida, a solução resultante (hexano + folhas) foi filtrada através de um funil. Esta sofreu um processo de evaporação através do evaporador rotatório a $69^{\circ} \mathrm{C}$ e o extrato foi colocado em banho-maria para total evaporação do solvente. Para a obtenção do extrato etanólico, foi utilizado o resíduo das folhas após 2 dias de repouso e o mesmo procedimento foi realizado, exceto que o solvente utilizado foi o etanol e a temperatura do rotaevaporador foi $100^{\circ} \mathrm{C}$.

\section{Prospecção fitoquímica dos extratos hexânico (EH) e etanólico (EE) de M. Charantia}

Os extratos obtidos foram submetidos a uma avaliação fitoquímica para detecção ou não de fenóis, taninos, antocianidinas, antocianinas, flavonóides, catequinas, flavonóis, flavononas, flavanonóis, xantonas, esteróides, triterpenóides, saponinas, alcalóides, em EH e EE das folhas de M.charantia de acordo com a metodologia descrita por Matos [12].

\section{Determinação da atividade antioxidante in vitro dos extratos hexânico (EH) e etanólico (EE) das folhas de M.charantia}

A atividade antioxidante dos extratos hexânico e etanólico das folhas de M.charantia foi determinada pelo método varredor de radical livre DPPH (1,1-difenil2-picrihidrazil) [17].

\section{Preparação do ungüento}

$\mathrm{O}$ ungüento foi obtido pela mistura de $10 \mathrm{e}$ ou $20 \%$ dos extratos (EH e EE) das folhas de $M$. charantia com uma base de vaselina e lanolina (1:2). As lesões controle foram tratadas com a base do ungüento, sem adição dos extratos.

\section{Animais de experimentação}

Foram utilizados seis (06) coelhos da raça Nova Zelândia, pesando $2 \mathrm{~kg}$, com idade de 2 a 6 meses, machos. Os animais foram adquiridos de um estabelecimento comercial, sendo submetidos a um período de quarentena em que foram vermifugados e observados quanto ao estado de saúde geral e só então, destinados à realização dos experimentos. Os animais foram separados em grupos e mantidos em gaiolas no Laboratório de Imunologia e Bioquímica (LIBA) na Universidade Estadual do Ceará (UECE), sob condições adequadas de higiene, luz e temperatura, recebendo ração comercial e água ad libitum. Os procedimentos experimentais foram realizados de acordo com as normas de experimentação animal do Colégio Brasileiro de Experimentação Animal (COBEA).

\section{Indução e tratamento das lesões experimentais}

Previamente, os coelhos sofreram anestesia geral realizada por via intramuscular na região do quadríceps, utilizando-se cloridrato de ketamina $44 \mathrm{mg} \cdot \mathrm{kg}^{-1}$, xilazina $4 \mathrm{mg} \cdot \mathrm{kg}^{-1}$ e valium $0,43 \mathrm{mg} \cdot \mathrm{kg}^{-1}$. Foram pro- 
duzidas seis lesões no dorso de cada animal, sendo três de cada lado, paralelamente a coluna vertebral a $2 \mathrm{~cm}$ de distância, entre a escápula e a tuberosidade ilíaca com um punch de $5 \mathrm{~mm}$ (técnica modificada), incluindo lesionamento da pele, tecido celular subcutâneo e músculo cutâneo do tronco. A identificação das feridas seguiu a sua localização, portanto, foram denominadas craniais direita (CRD), craniais esquerda (CRE), centrais direita (CND), centrais esquerda (CNE), caudais direita (CDD) e caudais esquerda (CDE) [3].

Em cada ferida, foi aplicada topicamente e de forma padronizada: CRD e CRE (base), CND e CNE (EH ou EE a $10 \%$ + base), CDD e CDE ( EH ou EE a $20 \%$ + base). Cada tratamento foi administrado uma vez ao dia no mesmo horário. As lesões do lado direito foram tratadas por 4 dias e as do lado esquerdo por 14 dias. No D4 e no D14, as lesões foram seccionadas e encaminhadas para análise histológica.

\section{Avaliação das lesões}

As lesões foram submetidas a avaliação macroscópica diária, verificando-se os seguintes parâmetros: edema, hiperemia e presença de exsudato [11].

Foi também realizado um estudo morfométrico visando a mensuração do halo da ferida no dia da indução da ferida no $4^{\circ}$ e $14^{\circ}$ dia pós-indução, através da colocação de plástico transparente sobre a ferida e demarcação com caneta de retroprojetor, submetendo-se este traçado a mensuração com planímetro. A área de retração da ferida foi calculada subtraindose a área previamente estipulada $\left(\mathrm{A}_{0}=5 \mathrm{~mm}\right)$ da área da ferida em D4 e D14 $\left(R=A_{0}-A\right)$. Os resultados das diferenças entre as feridas experimentais e controle foram comparadas.

Após a realização do protocolo anestésico, similar ao utilizado para indução das feridas, as lesões foram removidas e submetidas a fixação em formol tamponado a $10 \%$ por $48 \mathrm{~h}$, seguida de desidratação em álcool a 70\%. As amostras foram embebidas em parafina e secções de $5 \mathrm{~mm}$ de espessura foram preparadas. As lâminas foram coradas com hematoxilinaeosina (H\&E) e observadas ao microscópio óptico. Para análise histopatológica foram avaliados três sítios de cada corte histológico (3 cortes/animal) em cada intervalo de tempo. Nestas áreas foi realizada a contagem do número de células mononucleares inflamatórias, fibroblastos e vasos sanguíneos de cada sítio (1000X).

\section{Análise estatística}

A análise de variância (ANOVA) foi realizada para todas as medidas obtidas relativas a área da ferida (mm), sendo os dados posteriormente submetidos ao teste $\mathrm{t}$ Student, aceitando-se $5 \%(\mathrm{P}<0,05)$ como nível de significância para interpretação dos resultados. Os resultados relativos à contagem de células e vasos foram tabulados e analisados através do teste estatístico Kruskall Wallis.

\section{RESULTADOS}

\section{Prospecção fitoquímica e atividade antioxidante in vitro dos extratos hexânico (EH) e etanólico (EE) de M. Charantia}

O estudo fitoquímico revelou a presença de esteróides e a ausência para alcalóides, saponinas, catequinas, taninos, fenóis, flavonas, flavonóis, leucoantocianidinas, xantonas, triterpenóides, resinas e alcalóides em ambos os extratos.

Os resultados da atividade antioxidante in vitro dos extratos (EH e EE) das folhas de Momordica charantia pelo método de varredura do radical livre DPPH demonstraram que o EE das folhas de $M$. charantia nas doses de 2,5 e $10 \mathrm{mg} \cdot \mathrm{mL}^{-1}$ apresentaram índice de varredura (IV) de 28,$66 ; 38,73$ e $39,75 \%$, respectivamente. $\mathrm{O} \mathrm{EH}$ das folhas de $M$. charantia nas doses de 2,5 e $10 \mathrm{mg} \cdot \mathrm{mL}^{-1}$ apresentaram IV de 40,07; 76,64 e 79,79\%, respectivamente. Os grupos controle BHT e quercetina apresentaram IV de 90,89 e $90,32 \%$, respectivamente. Desta forma, o EH demonstrou maior capacidade em captar os radicais livres.

\section{Avaliação macroscópica}

A avaliação macroscópica foi realizada diariamente até o D14. Nesse estudo foi observado que as lesões teciduais experimentais nos grupos controle e tratados com o EE (10 e 20\%) de M. charantia obedeceram à mesma seqüência de eventos dependente do tempo. No entanto, os grupos tratados com EH (10 e $20 \%$ ) apresentaram uma evolução cicatricial mais precoce em relação ao controle. No decorrer de toda a investigação foram observados que os sinais de inflamação como edema, hiperemia e presença de exsudato foram discretos nas feridas tratadas com ungüento à base de $\mathrm{EH}$. Nos animais tratados com ungüento à base de $\mathrm{EE}$, foi verificada moderada exsudação a partir do quarto dia permanecendo até o último dia analisado (D14).

\section{Estudo morfométrico}

A Tabela 1 demonstra os efeitos do EH e EE das folhas de M.charantia sobre a área de retração de lesões cutâneas determinada pela mensuração do halo da ferida após 4 e 14 dias de tratamento. 
O estudo morfométrico revelou que houve aumento significativo $(\mathrm{P}<0,05)$ da área de retração das feridas em todos os tratamentos no decorrer dos dias analisados.

Os ungüentos associados ao EH (10 e 20\%) induziram maior área de retração em relação ao controle $(\mathrm{P}<0,05)$. Em contrapartida os ungüentos a base de EE não exerceram efeito significativo na retração das feridas.

\section{Estudo histológico}

A contagem de células mononucleares, fibroblastos e vasos sanguíneos na região da lesão para todos os tratamentos avaliados está apresentada nas Tabelas 2, 3 e 4 .

A Tabela 2 indica que o ungüento que demonstrou capacidade de modular a resposta inflamatória foi aquele associado ao EH em ambas as concentrações, já que este gerou uma redução significativa $(\mathrm{P}<0,01)$ na quantidade de células mononucleares em relação ao controle nos dois intervalos de tempo analisados.

No tocante a quantificação de fibroblastos expressa na Tabela 3 foi observado que houve uma redução significativa $(\mathrm{P}<0,01)$ no número de fibroblastos entre os grupos tratados com o ungüento a base de $\mathrm{EH}$ (10 e a 20\%) em relação ao controle nos tempo 14 dias.

A Tabela 4 indica que a quantidade de vasos sanguíneos foi significativamente menor $(\mathrm{P}<0,01)$ no grupo tratado com o ungüento associado ao $\mathrm{EH}$ (10 e 20\%) em relação ao controle no tempo de 14 dias.

$\mathrm{O}$ EE não apresentou ação sobre o processo de regeneração cutânea quanto aos parâmetros analisados, não diferindo significativamente das lesões tratadas apenas com a base do ungüento $(\mathrm{P}>0,01)$.

\begin{tabular}{|c|c|c|c|c|}
\hline \multirow{2}{*}{\multicolumn{2}{|c|}{ Tratamentos }} & \multirow{2}{*}{ Concentração (\%) } & \multicolumn{2}{|c|}{ Área $(\mathrm{mm})$} \\
\hline & & & D4 & D14 \\
\hline \multirow{5}{*}{$\begin{array}{l}\text { Ungüento } \\
\text { (Lanolina - } \\
\text { Glicerina 2:1) }\end{array}$} & Controle & - & $2,13 \pm 0,06^{\mathrm{a}, \mathrm{A}}$ & $2,78 \pm 0,06^{a, B}$ \\
\hline & \multirow{2}{*}{ EH } & 10 & $2,58 \pm 0,08^{b, A}$ & $3,37 \pm 0,09^{\mathrm{b}, \mathrm{B}}$ \\
\hline & & 20 & $2,69 \pm 0,17^{b, A}$ & $3,50 \pm 0,12^{\mathrm{b}, \mathrm{B}}$ \\
\hline & \multirow{2}{*}{ EE } & 10 & $2,17 \pm 0,05^{\mathrm{a}, \mathrm{A}}$ & $2,88 \pm 0,10^{\mathrm{a}, \mathrm{B}}$ \\
\hline & & 20 & $2,21 \pm 0,11^{\mathrm{a}, \mathrm{A}}$ & $2,96 \pm 0,10^{\mathrm{a}, \mathrm{B}}$ \\
\hline
\end{tabular}

Letras minúsculas diferentes indicam diferença significativa $(\mathrm{P}<0,05)$ na mesma coluna em relação ao grupo controle. Letras maiúsculas indicam diferença significativa $(\mathrm{P}<0,05)$ entre D4 e D14.

Tabela 2. Efeito dos tratamentos com os ungüentos à base dos extratos hexânico (EH) e etanólico (EE) sobre as células mononucleares com 4 (D4) e 14 (D14) dias de tratamento. Os dados são representados em média e desvio padrão ( $\mathrm{n}=3$ animais/grupos).

\begin{tabular}{|c|c|c|c|c|}
\hline \multirow{2}{*}{\multicolumn{2}{|c|}{ Tratamentos }} & \multirow{2}{*}{ Concentração (\%) } & \multicolumn{2}{|c|}{$\mathrm{N}^{\circ}$ células mononucleares } \\
\hline & & & D4 & D14 \\
\hline \multirow{5}{*}{$\begin{array}{l}\text { Ungüento } \\
\text { (Lanolina - } \\
\text { Glicerina 2:1) }\end{array}$} & Controle & - & $32,66 \pm 0,83$ & $12,12 \pm 0,14$ \\
\hline & \multirow{2}{*}{ EH } & 10 & $14,83 \pm 1,52$ & $4,20 \pm 0,18^{* *}$ \\
\hline & & 20 & $13,45 \pm 1,62$ & $4,33 \pm 0,13^{* *}$ \\
\hline & \multirow{2}{*}{ EE } & 10 & $27,12 \pm 1,00$ & $10,40 \pm 0,10$ \\
\hline & & 20 & $28,35 \pm 1,75$ & $10,83 \pm 0,07$ \\
\hline
\end{tabular}


Tabela 3. Efeito dos tratamentos com os ungüientos à base dos extratos hexânico (EH) e etanólico (EE) sobre os fibroblastos com 4 (D4) e 14 (D14) dias de tratamento. Os dados são representados em média e desvio padrão ( $\mathrm{n}=3$ animais/grupos).

\begin{tabular}{ccccc}
\hline \multirow{2}{*}{ Tratamentos } & & Concentração (\%) & \multicolumn{2}{c}{ No $^{2}$ fibroblastos } \\
\cline { 4 - 5 } & Controle & - & $26,00 \pm 2,25$ & D14 \\
\cline { 3 - 5 } & \multirow{2}{*}{ EH } & 10 & $20,90 \pm 0,86$ & $14,66 \pm 1,16^{*}$ \\
$\begin{array}{c}\text { Ungüento } \\
\text { (Lanolina }-\end{array}$ & & 20 & $21,43 \pm 1,28$ & $16,16 \pm 1,23^{\circ}$ \\
Glicerina 2:1) & EE & 10 & $21,84 \pm 0,83$ & $22,55 \pm 1,37$ \\
& & 20 & $22,46 \pm 1,02$ & $21,98 \pm 1,93$ \\
\hline
\end{tabular}

"Indica diferença significativa $(\mathrm{P}<0,01)$ no $\mathrm{D} 14$ em relação ao grupo controle.

Tabela 4. Efeito dos tratamentos com os ungüentos à base dos extratos hexânico (EH) e etanólico (EE) sobre a formação dos vasos sangüíneos com 4 (D4) e 14 (D14) dias de tratamento. Os dados são representados em média e desvio padrão ( $\mathrm{n}=3$ animais/grupos).

\begin{tabular}{|c|c|c|c|c|}
\hline \multirow{2}{*}{\multicolumn{2}{|c|}{ Tratamentos }} & \multirow{2}{*}{ Concentração (\%) } & \multicolumn{2}{|c|}{$\mathrm{N}^{\circ}$ vasos sanguíneos } \\
\hline & & & D4 & D14 \\
\hline \multirow{5}{*}{$\begin{array}{l}\text { Ungüento } \\
\text { (Lanolina - } \\
\text { Glicerina 2:1) }\end{array}$} & Controle & - & $7,23 \pm 0,50$ & $6,78 \pm 0,70$ \\
\hline & \multirow[b]{2}{*}{ EH } & 10 & $6,48 \pm 0,56$ & $4,96 \pm 0,67$ \\
\hline & & 20 & $6,74 \pm 0,40$ & $5,03 \pm 0,42$ \\
\hline & \multirow{2}{*}{ EE } & 10 & $6,97 \pm 0,71$ & $5,74 \pm 0,72$ \\
\hline & & 20 & $6,39 \pm 0,79$ & $5,93 \pm 0,73$ \\
\hline
\end{tabular}

"Indica diferença significativa $(\mathrm{P}<0,01)$ no $\mathrm{D} 14$ em relação ao grupo controle.

\section{DISCUSSÃO}

A importância da pele como barreira de proteção contra agentes nocivos [13] aliada a alta incidência de feridas resultantes de acidentes traumáticos em animais domésticos motivaram a realização deste experimento. Além disto, os constantes avanços científicos no ramo da fitoterapia levando a mudanças nos vários conceitos tradicionais no tratamento de feridas reforçaram a necessidade de estudos nesta área.

As etapas do processo de cicatrização foram observadas no presente trabalho tanto nas lesões tratadas com EH e EE de $M$. charantia, como nas nãotratadas, conforme os dias analisados. A evolução cicatricial das feridas experimentais foi considerada clinicamente normal.

A análise macroscópica revelou que a presença de exsudato no grupo controle e tratado com EE prejudicou a cicatrização, já que este é capaz de promover a desagregação do tecido de granulação em formação e o desenvolvimento de microorganismos.

As infecções microbianas causam um aumento nas complicações no processo de cicatrização. Estudos prévios revelaram que a M.charantia apresenta um amplo espectro de atividade antimicrobiana [7].

A medida da retração da área do processo inflamatório revelou que durante o tratamento, houve diferença significativa $(\mathrm{P}<0,01)$ nas áreas de retração das lesões que receberam ungüento a base do $\mathrm{EH}$ de $M$. charantia, as quais cicatrizaram com maior rapidez que às lesões controle e as tratadas com ungüento associado ao EE.

O influxo de macrófagos e neutrófilos para o sítio da lesão durante a fase inflamatória revelou uma redução $(\mathrm{P}<0,01)$ destas células nos grupos tratados com o ungüento à base de EH (10 e 20\%) em relação ao controle no $\mathrm{D} 4$, indicando que este tratamento foi 
capaz de modular o processo inflamatório neste intervalo de tempo.

Com a presença local de macrófagos e a produção e liberação dos mediadores químicos produzidos por eles, a migração e ativação de fibroblastos é intensificada. Essas células são as principais responsáveis pela formação de tecido de granulação, sintetizando ácido hialurônico, fibronectina, colágenos tipos I e II, elastina e proteases, como a colagenase, importante para o debridamento e o remodelamento das fibras colágenas. $\mathrm{O}$ aumento de fibroblastos na regeneração tecidual encontra seu ápice na fase proliferativa deste processo, que ocorre geralmente entre o $3^{\circ}$ e o $10^{\circ}$ dia após a lesão. Para a eficiência da fibroplasia é necessária a ocorrência em paralelo da neovascularização da região, já que esta permite a troca de gases e a nutrição das células metabolicamente ativas [4,5]. Além da ação direta de fatores de crescimento sobre as células da vasculatura, a indução da angiogênese é, em parte, creditada à baixa tensão de oxigênio característica que ocorre no centro de uma ferida [8].

No início da fase de remodelação, que corresponde aos grupos analisados no D14 neste experimento, observa-se redução no número de células mononucleares, fibroblastos e vasos sanguíneos (Tabelas 2,3 e 4 , respectivamente) e isto se justifica pela mudança de fase do processo inflamatório.

Numa etapa avançada do reparo tecidual acredita-se que os fibroblastos estejam relacionados com o fenômeno de remodelação dos feixes de colágeno, no sentido de conferir maior resistência a este tecido lesionado [15]. Isto reforça ainda mais a idéia de que o EH acelerou a atividade de fibroblastos fazendo com que o tecido lesionado apresentasse uma organização muito maior em comparação ao controle.

Nos grupos experimentais tratados com ungüento à base do $\mathrm{EH}$ houve uma redução significativa no número de fibroblastos e vasos sanguíneos em relação ao controle no D14, sugerindo que este extrato acelerou a reparação tecidual na fase tardia da reação inflamatória, possibilitando o alcance da fase de remodelamento mais precocemente que os demais grupos.

A sinergia de todos esses fatores avaliados pode estar envolvida com a regeneração cutânea observada nas lesões tratadas com os extratos estudados. Os efeitos sinérgicos foram mais pronunciados nas lesões tratadas com ungüento associado ao EH de $M$. charantia, e isso têm sido atribuído às propriedades antiradicais observadas no extrato hexânico e aos constituintes imunoativos presentes no extrato. No entanto, maiores estudos são necessários para desvendar esse mecanismo de ação.

\section{CONCLUSÃO}

O ungüento associado ao extrato hexânico (EH) das folhas de M.charantia, dentro dos parâmetros utilizados, demonstra ser eficaz por acelerar o processo de regeneração cutânea.

Agradecimentos. À Fundação Cearense de Amparo a Pesquisa (FUNCAP), por ter concedido apoio financeiro. Agradecimento especial à $\operatorname{Dr}^{\mathrm{a}}$ Selene Maia de Morais.

\section{REFERÊNCIAS}

1 Au T.K, Collins R.A., Lan T.L., Ng T.B., Fong W.P. \& Wan D.C. 2000. The plant ribossome inactivating proteins luffin and saporin are potent inhbitors of HIV-1 integrase. FEBS Letters. 471: 169-172.

2 Cunnick J.E., Sakamoto K., Chapes S.K., Fortner G.W \& Takemoto D.J. 1990. Induction of tumor cytotoxic immune cells using a protein from the bitter melon (Momordica charantia). Cellular Immunology. 126: 278-289.

3 Dorneles D., Wouk A.F., Pontarolo R. \& Oliveira A.B. 2003. Efeito de Aloe Vera Linné sobre a cicatrização de feridas de pele em coelhos. In: VII Congresso Virtual Hispanoamericano de Anatomia Patológica y I Congresso de Preparaciones Virtuales por Internet.(Pará, Brasil). pp. 39-46.

4 Eckersley J. R. T. \& Dudley H. A. F. 1998. Wound and wound healing. British Medical Bulletin. 44: 423-436.

5 Guidugli-Neto J. 1987. The effect of roentgen radiation on the capillary sprontsonal superficial loops of granulation tissue I: quantitative study of the vascular volume. Revista de Odontoologia da Universidade de São Paulo. 1: 6-8.

6 Johnston D. E. 1990. Wound healing in skin. Veterinary Clinics of North America: small animal practice. 20: 1-25.

7 Khan M.R. 1998. Momordica charantia and Allivum sativum: broad-spectrum antibacterial activity. Korean Journal of Pharmacognosy. 20: 151-158.

8 Knighton D. R., Silver I. \& Hunt T. K. 1981. Regulation of wound-healing angiogenesis-effect of oxygen gradients and inspired oxygen concentration. Surgery. 90: 262- 270.

9 Lee-Huang S., Huang P. L., Cheng H. C., Huang P. L., Bourinbaiar A., Huang H. I. \& Pung H. F. 1995. Anti-HIV and antitumor activities of recombinant MAP30 from bitter mellon. Gene. 61: 151-156. 
10 Leung S.O., Yeung H.W. \& Leung K.N. 1987. The immunosuppressive activities of two abortifacient proteins isolated from the seeds of bitter melon (Momordica charantia). Immunopharmacology. 13: 159-171.

11 Martins P.S., Alves A.L.G., Hussni C.A., Sequeira J.L., Nicolleti J.L.M. \& Thomasian A. 2003. Comparação entre fitoterápicos na cicatrização de pele em eqüinos. Archives of Veterinary Science. 8: 1-7.

12 Matos F.J.A. 1997. Introdução a Fitoquímica Experimental. $2^{\mathrm{a}}$ edição. Fortaleza: Imprensa Universitária, Universidade Federal do Ceará. 139p.

13 Oliveira H.P. 1992. Traumatismo nos animais domésticos. Cadernos Técnicos da Escola de Veterinária de Belo Horizonte. $1: 1-57$

14 Ribak S.M., Lin J.J. \& Newton D.L. 1994. In vitro anti-tumor activity of the plant ribossome inactivating proteins MAP30 and GAP31. International Journal of Oncology. 5: 88-94.

15 Simões M.J., A. Uzunian, O.A. Mora \& W.S. Sasso. 1985. Aspectos ultra-estruturais do processo de reparação da pele de ratos albinos. Revista Pauista de Medicina. 103: 123-126.

16 Virdi J., Sivakami S., Shahani S., Suthar A.C. Banavalikar M.M. \& Biyani M.K. 2003. Antihyperglycemic effects of three extracts from Momordica charantia. Journal of Ethnopharmacology. 88: 107-111.

17 Yepez B., Espinosa M., López S. \& Bolamos G. 2002. Producing antioxidant fractions from herbaceous matrices by supercritical fluid extraction. Fluid Phase Equilibria. 194: 879.

18 Yesilada E., Sezik E., Honda G., Takaishi Y., Takeda Y. \& Tanaka T. 1999. Traditional medicine in Turkey IX: folk medicine in north-west Anatolia. Journal of Ethnopharmacology. 64: 199-206. 